\title{
Effectiveness of Teacher Selected Strategies on Students' Academic Performance in Mathematics, a case of form three students.
}

\author{
Dr. Nandwa Marble Odhiambo \\ Department of Science and Mathematics Education \\ Masinde Muliro University of Science and Technology.
}

\begin{abstract}
Mathematics is a compulsory subject to all students. It is regarded as a career subject since anything students do after high school revolves around mathematics. Teachers of mathematics always strive to improve students' performance in mathematics. They always make sure that they complete the syllabus to give students a chance to do better in mathematics. Despite the importance of mathematics, most students in many schools still fail mathematics Examinations. The performance over the years has been persistently very poor. The purpose of this study was to find out which of the strategies of learning mathematics improves students achievement in mathematics; individualization for Mastery approach (IMA) or completing the syllabus (CSA).This entailed the use of the two approaches in the learning of Vectors 11; a form three mathematics topic. This study investigated the relationship between the achievement of students where teachers of mathematics used Individualization for Mastery approach (IMA) and those ones where the teachers worked hard to complete the syllabus. The theoretical framework which guided this study was social constructivism theory. The study adopted a pre-test post-test non-equivalent group design. The target population for this study was all the form three students in 39 secondary schools in Mumias subcounty Kakamega County, Kenya. Stratified random sampling was used to select schools that took part in the study. The strata were Boys' schools, Girls' schools and co-educational schools. From girls' and coeducation schools, the researcher randomly selected three schools from each out of 10 and 26 schools respectively, while from boys' schools; two schools were selected using saturation sampling giving a total of eight (8) schools that participated in the study. One stream selected randomly from each sampled school took part in the study. Experimental group had a total of 126 students while the Control group had 130 students. The Control group used completing the syllabus approach (CSA) while the Experimental group used Individualization for Mastery (IMA) approach. Each group (CSA and IMA) comprised of four schools selected randomly from the eight schools. The students' Achievement test was used to collect data. The instrument was developed basing on the objectives and given to the experts in Mathematics Education to validate. To determine the reliability of the instrument, Split half technique was employed since it involves only one testing session and it eliminates chance error. Data was analyzed using both descriptive and inferential statistics. Results indicate that there is a significant difference in achievement between students who used Individualization for Mastery (IMA) approach and those who used completing the syllabus (CSA) strategy in favor of the (IMA) group.
\end{abstract}

Key words: individualization, mastery, completion of the syllabus, achievement

\section{Introduction}

Poor performance in mathematics has remained a problem to all [10]. The improvement of instruction has been a goal of educators as far back as the teachings of the Greek philosopher Socrates. It was to improve the instructional experience for the individual learner [16]. 
A mathematical concept or skill is said to have been mastered when a student can represent it in multiple ways, can frame it in a different way, has the mathematical language to communicate related ideas, and can apply the concept to new problems in unfamiliar situations independently [4].Mastery is a journey and longterm goal, achieved through exploration, clarification, practice and application over time [6]. At each stage of learning, pupils should be able to demonstrate a deep, conceptual understanding of the topic and be able to build on this over time. This is not about just being able to memorize key facts and procedures, which tends to lead to superficial [7].

A strong subject knowledge and positive teacher mind set are key to student success in mathematics. It is not the case that some students can do mathematics and others cannot. Clearly and emphasizing the value of mathematics education, pupils are encouraged to build confidence and resilience [9]. Abilities are neither fixed nor innate, but can be developed through practice, support, dedication and hard work [8]. Natural talent is just a starting point and does not determine who has more or less potential to achieve. A positive teacher mindset in mathematics encourages a love of learning and resilience that enables everyone to achieve [17].

All students are entitled to learn key concepts and skills. A scheme of work based around the principles of mastery really can be suitable for all [14]. They should have the opportunity to stay together and work through new content as a whole group [18]. While mastery schemes of work may be challenging for some, the vast majority should be aiming for this standard. In extreme cases, where students have Considerable learning difficulties, individual schools may want to put some alternatives in place [11]. It is important that high-attaining students fully understand key number concepts, rather than simply memorize a process.

All students benefit from deepening their conceptual understanding of mathematics, regardless of whether they've previously struggled or excelled. Students must be given time to fully understand, explore and apply ideas, rather than accelerate through new topics. This approach enables pupils to truly grasp a concept, and the challenge comes from investigating it in new, alternative and more complex ways [4].Objects, pictures, words, numbers and symbols are everywhere. The mastery approach incorporates all of these to help pupils explore and demonstrate mathematical ideas, enrich their learning experience and deepen understanding [13]. Together, these elements help cement knowledge so pupils truly understand what they've learnt. All pupils, when introduced to a key new concept, should have the opportunity to build competency in this topic by taking this approach. Pupils are encouraged to physically represent mathematical concepts [5]. Objects and pictures are used to demonstrate and visualize abstract ideas, alongside numbers and symbols.

Students should have the opportunity to use concrete objects and manipulative to help them understand and explain what they are doing. Students should then build on this concrete approach by using pictorial representations [12]. These representations can then be used to reason and solve problems. With the foundations firmly laid, students should be able to move to an abstract approach using numbers and key concepts with confidence.

Mathematical problem solving is at the heart of most teachers of mathematics. Students are encouraged to identify, understand and apply relevant mathematical principles and make connections between different ideas. This builds the skills needed to tackle new problems, rather than simply repeating routines without a secure understanding [3].Mathematical concepts are explored in a variety of representations and problemsolving contexts to give students a richer and deeper learning experience. Students combine different concepts to solve complex problems, and apply knowledge to real-life situations [14]. The way students speak and write about mathematics transforms their learning. Mastery approaches use a carefully sequenced, structured approach to introduce and reinforce mathematical vocabulary [8]. Pupils explain the mathematics in full sentences. They should be able to say not just what the answer is, but how they know it is right. This is key to building mathematical language and reasoning skills $[2,8]$.

Students should be able to recall and apply mathematical knowledge both rapidly and accurately. However, it is important to stress that fluency often gets confused for just memorization - it is far more than this [1]. As well as fluency of facts and procedures, pupils should be able to move confidently between contexts and representations, recognize relationships and make connections in mathematics (4). This should help students 
develop a deep conceptual understanding of the subject. Frequent, carefully designed, intelligent practice will help them to achieve a high level of fluency [15].

\section{i. Statement of the problem}

For students to master mathematics concepts, Individualization for Mastery instruction approach must be embraced. Individualization instruction is defined as that in which each student participates in setting his own goal, woks at his own rate (either alone or as a member of a small group)...and participates in evaluating his own progress [3]. Individualization instruction focuses on the needs of the individual student. Teaching is specific and targets one need at a time. This teaching method can be used on its own or it can be part of differentiated teaching [7]. Some students who receive individualized instruction need teachers to help them understand and learn. Other students using the same teaching method can skip topics they already know and go on to advanced information.

Individualization for Mastery instruction (IMA) approach entails teachers planning carefully and collaboratively to ensure they are using meaningful data to gain insights on how individual children are progressing toward a goal $[1,16]$. Lengthy whole-group lessons are not important in this case; rather more play-based centers and inquiry-based projects are focused on [5]. The centers and projects complimented by strategic use of current technological resources allow teachers to design engaging lessons that tap into the natural curiosity of each child (15). Teachers provide opportunities for children to approach their learning in a variety of ways which provides more opportunities to retain information which improves moral and excitement for learning (2).

Completing the syllabus approach (CSA) is the traditional instruction in which students are taught as a class. It includes homogeneous or heterogeneous grouping and does not preclude the use of audio-visual aids, group work, or any other techniques traditionally used by teachers to help students learn. The main aim of traditional approach is to complete the syllabus. This study inquired on the effect of Individualization for Mastery learning Approach (IMA) in enhancing the academic achievement of mathematics.

\section{ii. The purpose of the study:-}

The purpose of the study is to investigate the influence of Individualization for Mastery instructional (IMA) approach on secondary school students' achievement in mathematics.

\section{iii. Objective of the study:-}

The study was guided by the following objective;

To find out the influence of Individualization for Mastery instructional approach (IMA) on secondary school students' achievement in mathematics.

\section{iv. Hypothesis of the study:-}

The study was guided by the following hypothesis:

HO$_{1}$ : there is no significant difference in the achievement between students taught Vectors 11 using Individualization for Mastery instructional approach (IMA) and their counterparts who used completing the syllabus approach (CSA).

\section{v. Significance of the study}

Educators find it difficult to solve the varied problems for young children. It therefore calls for a lot of planning in order to assess them to facilitate their benefit.

Individualization for Mastery (IMA) instruction prepares children to become active and effective learners developing the skills needed to live long as learners in an ever changing world. It also helps children to retain information they have learned and increase their glamour for learning mathematics. It also helps students to learn at their own pace towards very challenging learning outcomes, 
Mastery learning aims to change the notion that everyone is on the same time schedule. It allows teachers to give students extra explanation and support during learning. Students are also given enough time to go over the learning material.

It has implications for professional development and training of teachers in that teachers of mathematics become mathematics resource persons, they have deep mathematical knowledge, and they know how to communicate to students while teaching mathematics. They always engage in improving their effectiveness in the learning of mathematics.

\section{Body text}

The study adopted pre-test post-test experimental design with two groups; Experimental and Control. The design involved random assignment of intact classes of students to two groups; one group being Experimental and another one being Control. Nonequivalent control group design was used in this study because it is not possible to randomly assign students taking part in the research to both Experimental and Control groups, therefore intact classes were preferred. Four classes fell in the Experimental category while the other four fell in the Control category. Out of a total of 1734 Form three students in Mumias sub-county, 256 were sampled out for the study. Students in the Control group were taught by the traditional /conventional method of completion of the syllabus (CSA) while their counterparts of Experimental group used individualization for mastery approach (IMA). Table 3.1 illustrates this study design.

Table 3.1: pre-test post-test non-equivalent group design

\begin{tabular}{|l|l|l|l|}
\hline Group & Pre-test & Treatment & Post-test \\
\hline C & $\mathrm{O}_{1}$ & X & $\mathrm{O}_{3}$ \\
\hline E & $\mathrm{O}_{2}$ & $X$ & $\mathrm{O}_{4}$ \\
\hline
\end{tabular}

Before embarking in class to be taught Vectors 11, students in both groups were given a pre-test $\left(\mathrm{O}_{1} \mathrm{O}_{2}\right)$ on vectors 1 (MAT 1) which they had learned in form two and therefore a prerequisite knowledge to Vectors 11. This was to determine whether they differed significantly before learning vector 11. The Experimental group was given the treatment while the Control group was denied the treatment. After completion of instruction on the topic Vectors 11, both groups received a post-test (MAT 2); an examination that was set on the content that had been taught to students. Data for both MAT 1 and MAT 2were analyzed using both descriptive and inferential statistics.

\section{Results and discussion:-}

The students' mathematics achievement tests (MAT1 and MAT 2) were used since they produced the results to be analyzed. The arithmetic mean and standard deviation of MAT 1 were calculated for both Experimental and Control groups and results were as shown in Table 4.1.

Table 4.1:-arithmetic mean and standard deviation on MAT pre-test scores

\begin{tabular}{|l|l|l|}
\hline Group & Pre-test mean $\frac{x}{100}$ & Pre-test standard deviation \\
\hline C & 40.20 & 16.34 \\
\hline E & 39.70 & 14.32 \\
\hline
\end{tabular}

An observation of Table 4.1 indicates that the pre-test mean score of the Experimental group was 39.70, while that of the Control group was 40.20. These results suggested that before the students were exposed to the lessons on Vectors 11, they had the same entry behavior. The difference between their mean score was 0.5, the Control group holding the top position. To determine whether there was any difference between the mean scores, an ANOVA of the pre-test results at $\alpha=0.05$ was calculated and the results are as shown in Table 4.2 
Table 4.2:- One way ANOVA on MAT 1

\begin{tabular}{|l|l|l|l|l|l|}
\hline SOURCE & D.F & S.S & M.S & Cal value & Cri value \\
\hline BETWEEN GROUPS & $2-1=1$ & 6.48 & 6.48 & \multirow{3}{*}{0} \\
\cline { 1 - 3 } WITHIN GROUPS & $256-2=54$ & 373540.52 & 1804.54 & \multirow{2}{*}{0.0035} & \multirow{2}{*}{3.84} \\
\cline { 1 - 3 } TOTAL & 355 & & & & \\
\hline
\end{tabular}

Significance at 0.05 level, critical value $0.0035<3.84$

From Table 4.2, the calculated F- Ratio (0.0035) was lower than the critical value (3.84). This implies that there exists no difference in achievement in mathematics between the Experimental and the Control groups. This indicates that the students were at the same level before they were exposed to mathematics lessons on the topic of Vectors 11. Further analysis using Scheffe post hoc analysis procedure also indicated that there existed no significant difference between the mean scores of the groups. It was therefore concluded that there was no significant difference between the achievement scores of the Experimental and the Control groups before learning of Vector 11 began.

After implementation of Individualized for Mastery Approach (IMA) in the learning of mathematics, the mean scores of both groups improved remarkably. The mean and standard deviation for post test results were calculated for Experimental and Control groups and the results recorded in Table 4.3.

Table 4.3:- Comparison of mean scores and mean gains on MAT1 and MAT2

\begin{tabular}{|l|l|l|l|l|}
\hline Group & No. of students & Pre-test mean & Post-test mean & deviation \\
\hline Control & 130 & 39.70 & 44.60 & +4.90 \\
\hline Experimental & 126 & 40.20 & 63.90 & +23.70 \\
\hline
\end{tabular}

Results in Table 4.3 indicate that the post-test mean scores for the Experimental group (63.90) were much higher than that of the Control group. The mean gain for the Experimental group (23. 70) was also much higher than for the Control group (4.90). The results indicate that although both groups benefited from the mathematics course, Experimental group were a head of the Control group by far. The big difference between the means of the pre-test results and the post-test results of the Experimental group was attributed to the use of Individualized for Mastery approach.

To provide a clear picture on the effectiveness of the Individualized for Mastery approach over the conventional method of completing the Syllabus approach (CSA), an ANOVA on the pre-test results was calculated to show if there is any significant difference between the mean scores of the two groups and the results were recorded in Table 4.4.

Table 4.4:- One way ANOVA on MAT2 post -test Results

\begin{tabular}{|c|c|c|c|c|c|}
\hline Source & D.F & S.S & M.S & F-ratio & Critical value \\
\hline Between Groups & $2-1=1$ & 15135.446 & 15135.446 & \multirow{3}{*}{5.142} & \multirow{3}{*}{3.84} \\
\hline Within Groups & $256-2=254$ & 750594.554 & 2943.59806 & & \\
\hline Total & 255 & 765730 & 18079.046 & & \\
\hline
\end{tabular}

Results from table 4.4 show that the calculated F-ratio (5.142) is greater than the critical value (3.84) indicating significant difference in achievement between the two groups. In addition to ANOVA, a t-test was calculated to show the direction of the difference and the results summarized in Table 4.5.

Table 4.5:- An independent samples t- test on MAT post- test results

\begin{tabular}{|l|l|l|l|l|l|l|l|}
\hline Group & $\mathrm{N}$ & Mean & S.D & D.F & Cal t & Cri t & Remark \\
\hline C & 130 & 44.70 & 16.60 & 255 & 12.05 & 1.658 & Sig difference \\
\hline E & 126 & 63.90 & 9.20 & & & & \\
\hline
\end{tabular}


From Table 4.5, the results of t-test indicate that the calculated t- value was greater than the critical t- value. This is a clear indication that the students who were taught by the Individualization for Mastery approach (IMA) performed very well in the MAT 2 as compared to their counterparts that used the traditional method of completing the Syllabus approach (CSA). It was therefore concluded that there was a significant difference in performance between IMA group and CSA groups. In addition, the Scheff post hoc analysis procedure was further carried out on the post- test results in order to find out whether there was a significant difference between the means of the two groups. The results were agreed with that of the $t-$ test $(E>C)$.

\section{Conclusion:-}

Mathematics mastery is an approach to mathematics education which is based on mastery learning in which most students are expected to achieve a high level of competence before progressing [3]. Individualization involves the teacher dealing with different students at different levels and unless he understands, he cannot move to the next level. These two approaches are dependent to one another since the result of individualized approach is mastery of the concept and they are the basis of this study. Individualized approaches cater for all students including the slow learners since the teacher meets them at every point of need.

The need for this study was prompted by poor performance of students in mathematics. There was need to assess the usefulness of Individualization for Mastery approach (IMA) in the teaching and learning of mathematics. The major objective for this study was to find out the influence of Individualization for Mastery instructional approach (IMA) on secondary school students' achievement in mathematics. The performance of students who used Individualization for Mastery instructional approach (IMA) was compared with that of the students who used the conventional method of competing the syllabus (CSA).Students who used Individualized for Mastery approach (IMA) showed high potential in the achievement of mathematics as compared to their counter parts who used the traditional method of Completion of the Syllabus approach (CSA). The working theory for this study was based on the fact that interaction is the main agent for any meaningful learning. Individualization requires that the teacher interacts with students at close range.

The findings of this study suggest that use of Individualization for Mastery instructional approach (IMA) is very effective but requires more time for teachers to interact with their students during learning of mathematics. The results were supported by [13] who said that all students become fluent in the fundamentals of mathematics, including through varied and frequent practice. They develop conceptual understanding and are able to recall and apply their knowledge rapidly and accurately to problems. The expectation is that the majority of students who use Individualization for Mastery approach (IMA) move through the programs of study at broadly the same pace. The results were also supported by [10, 18] who said that (IMA) deepens knowledge of concepts and procedures, ensures what is learnt is sustained over time, and cuts down the time required assimilating and mastering later concepts and techniques.

The implications of the findings of this study reveal that Individualization for Mastery approach (IMA) is the desired approach for students to achieve reasonably in mathematics. It requires more time but it has good fruits for teachers of mathematics. This research was carried out at a time when the new curriculum is just setting in (competency based curriculum).

\section{Recommendations}

Whenever teachers of mathematics want their students to excel in mathematics (which is the goal of learning mathematics) they should embrace use of Individualization for Mastery instructional (IMA) approach. This research has shown that students who used this approach excelled more than those ones whose teachers were striving to complete the syllabus.

Use of Individualization for Mastery (IMA) approach encourages students since the slogan is 'mathematics can be done by all'. In addition, the interaction between the teacher and the student is enhanced since the teacher meets with each and every student to deal with the problem. 
Most importantly the ministry of Education should not limit the time students are supposed to learn mathematics in the name of completing the syllabus rather they should allow enough time for the teacher of mathematics to interact with the learner.

\section{References}

[1] Bloom, B. S. (1968). Learning for Mastery. Instruction and Curriculum. Regional Education Laboratory For the Carolinas and Virginia, Topical Papers and Reprints, Number 1. Evaluation Comment. Washington, D.C., USA: Office of Education.

[2] Boyd, P., \& Ash, A. (2018). Teachers framing exploratory learning within a text-book based Singapore Maths mastery approach. Teacher Educator Advancement Network Journal,10(1),62 73.Retrievedfrom: https://ojs.cumbria.ac.uk/index.php/TEAN/article/view/442.

[3] Cross, D. I. (2009). Alignment, cohesion and change: examining Mathematics teachers' belief structures and their influence on instructional practices. Journal of Mathematics Teacher Education, 12, 325-346.https//doi.org/10.1007/s10857-009-9120-5.

[4] Drury, H. (2015) Mastering Mathematics. 1st edn. Oxford: Oxford University Press.

[5] Guskey, T.R. (2007) 'Closing Achievement Gaps: Revisiting Benjamin S. Bloom's "Learning for Mastery", Journal of Advanced Academics 19(1), pp. 8-31.

[6] Guskey, Thomas. (2010). Lessons of Mastery Learning. Educational leadership: journal of the Department of Supervision and Curriculum Development, N.E.A. 68. 52-57.

[7] Guskey, T. (1987) 'The essential elements of Mastery Learning', The Journal of Classroom Interaction, 22(2), pp. 19-22.

[8] Jerrim, J. and Vignoles, A. (2016) 'The Link between East Asian 'Mastery' Teaching Methods and English Children's Mathematics Skills', Economics of Education Review, 50, pp. 29-44.

[9] Kent and Medway Maths Hub (2016) 'Elements of Mastery, available at http://www.elementsofmastery.org/ (Accessed 20th April 2018)[16] MCGAW, DICKINSON. 1975. "Personalized Systems of Instruction." Paper prepared for the annual meeting of the America Political Science Association, San Francisco.

[10] McCourt, M (2019). Teaching for Mastery. Woodbridge: John Catt Education

[11] NAUMES, MiKe. 1977. "The Keller Plan: A Method for Putting the Responsibility of Learning Upon the Student." Perspectives 1977:1-7.

[12] NCTM (2000).Principles and standards for school mathematics. Reston, VA: National Council.

[13] National Centre for Excellence in Teaching Mathematics (2016) 'Mastery Explained', available at https://www.ncetm.org.uk/resources/49450 (accessed 20th April 2018)

[14] OLDS, HenRY F. 1985. "The Microcomputer and the Hidden Curriculum." Computers in Schools 2 (1):3-14.

[15] Postlethwait, Samuel n.; NovaK, Joseph D.; and Murray, Hallard Thomas. 1972. The Audio-Tutorial Approach to Learning. Minneapolis, MN: Burgess.

[16] SNORTLAND, RoBERT K. 1982. "An Individualized Teaching Approach: Audio-Tutorial." College Teaching Monograph. ERIC Document ED 226656. Bismarck: University of North Dakota.

[17] Webb N.M. (1985). Student interaction. In R. Slavin (Ed), Learning to Cooperate. Cooperating to Learn, A Research Summary. New York: Plenum Press

[18] Webb N.M. (1989). Student Interaction and Mathematics Learning in Small Groups. In N. Davidson and R. Dees (Eds), Research in Small Group Cooperative Learning and Mathematics, A Monograph of the Journal for Mathematics Education. 